Gut, 1971, 12, 102-106

\title{
Pyloric incompetence in chronic non-specific lung disease
}

\author{
MICHAEL BEELEY AND PAUL GRECH
}

From the Departments of Internal Medicine and Radiology, Northern General Hospital, Sheffield

SUMMARY Of 19 patients with chronic non-specific lung disease, chosen without reference to dyspeptic symptoms, $17(89 \%)$ exhibited duodenogastric reflux of barium indicating pyloric incompetence. In the one patient who proved to have a gastric ulcer the amount of reflux diminished when the ulcer healed.

The degree of pyloric incompetence was not found to be related to the severity of arterial blood gas or $p \mathrm{H}$ disturbance or to the presence of right heart failure. All patients who exhibited reflux had evidence of obstructive airways disease and most were receiving bronchodilators.

We believe that reflux of detergent bile into the stomach may explain the high incidence of dyspepsia and acute gastric ulceration in chronic non-specific lung disease.

Reports that bile appears in the stomach more frequently in gastric than in duodenal ulcer (James and Pickering, 1949; Watkinson, 1951) suggested that this might be a factor in the production of gastric ulcer. Duodenogastric reflux of barium in the majority of patients with gastric ulcer was demonstrated by Capper, Airth, and Kilby (1966) and a subsequent study by Flint and Grech (1970) confirmed this finding. The possible importance of bilious reflux in predisposing to gastric ulceration has been emphasized by demonstrating interference by bile salts with the integrity of the gastric mucosal barrier (Davenport, 1968) and by showing that mucosal damage due to acid may result (Overholt and Pollard, 1968). The association of gastric ulcer and duodenal regurgitation has recently been reviewed by Delaney, Cheng, Butler, and Ritchie (1970).

There have been many reports of an increased incidence of peptic ulcer in obstructive airways disease commencing with a paper in 1952 by Green and Dundee. Though many authors have grouped together acute and chronic ulcers of both stomach and duodenum, Flint and Warrack (1958) reported acute gastric ulcers at necropsy in $17 \%$ of 87 patients with diffuse emphysema.

We postulated that in patients with chronic chest disease competence of the pylorus might be disturbed and therefore predispose to a high incidence of gastric ulceration. The present study examines pyloric competence in a group of patients with chronic non-specific lung disease.

Received for publication 6 October 1970.

\section{Patients}

Nineteen patients with chronic non-specific lung disease volunteered to take part in the study. They were chosen without reference to dyspeptic symptoms and, after inclusion in the series, the chest disease was further classified according to the five criteria given below. The patients investigated were, with the exception of case 19, all males; their ages ranged from 22 to 66 years (mean 54 years).

\section{CHRONIC BRONCHITIS}

The MRC Questionnaire on Respiratory Symptoms (1966) was completed for all patients and patients were labelled 'chronic bronchitis' only if they fulfilled the criteria for 'chronic bronchitis syndrome' laid down by the College of General Practitioners study group on respiratory diseases(1961) or if they had 'persistent cough, phlegm, and chest illness' as judged by the questionnaire. Of the patients who did not fulfil these criteria, none had chronic increase in the volume of bronchial secretion sufficient to cause expectoration.

\section{EMPHYSEMA}

Current postero-anterior and lateral chest radiographs were examined for characteristics of emphysema as described by Simon (1964) with due reference to lung size, cardiovascular changes, and bullae (Fig. 1). They were then labelled as definite emphysema $(+)$ or probable emphysema $( \pm)$ as appropriate; there is good correlation between a radiological diagnosis judged by these criteria and 


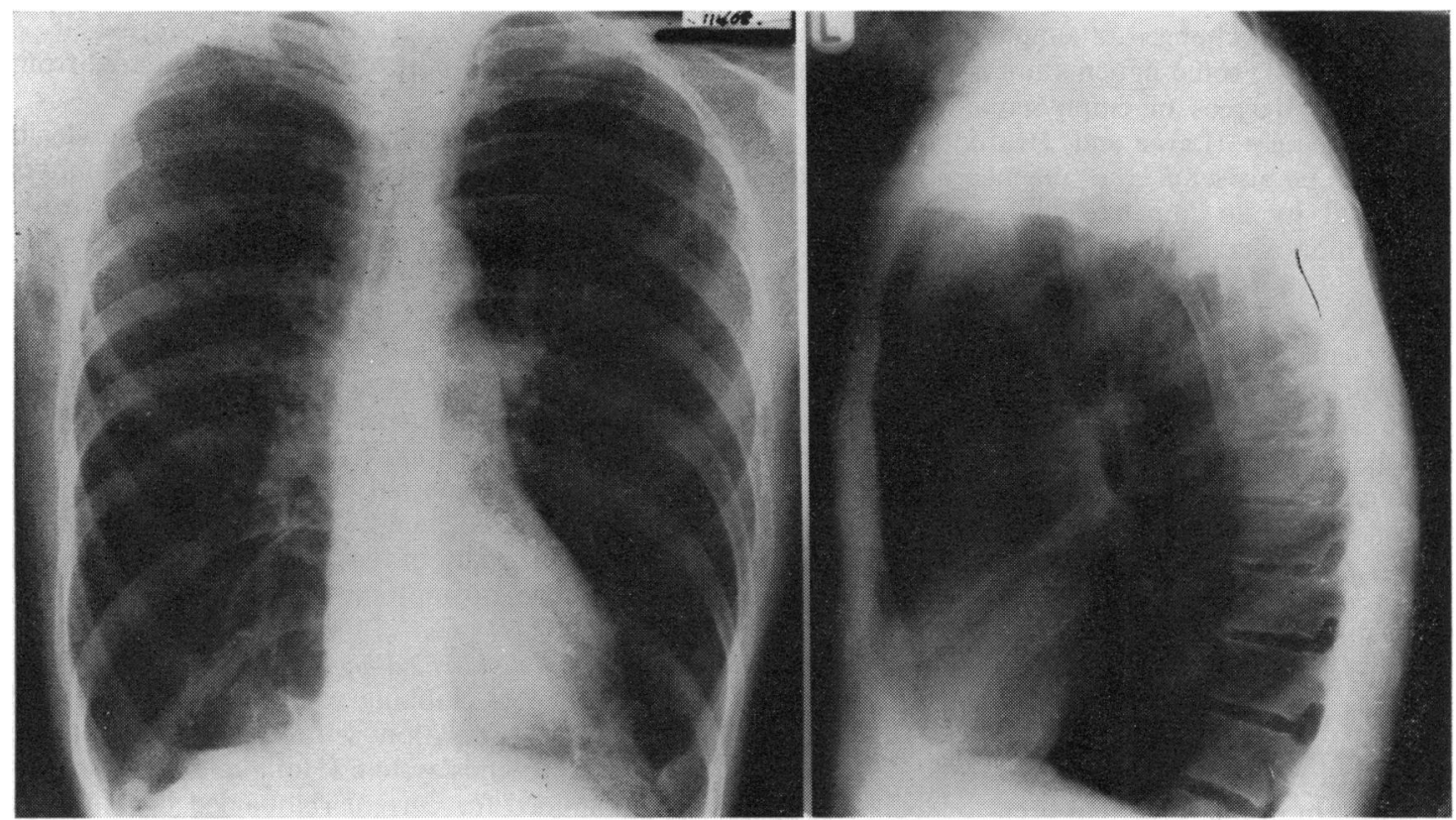

Fig. 1. Case 8, a male aged 59 years. Postero-anterior and lateral chest radiographs showing a flat, low diaphragm with increased retrosternal translucent area, enlargement of the pulmonary trunk, and tapering of the peripheral vessels. The diffusion capacity for $\mathrm{CO}$ was diminished, in keeping with the radiological diagnosis of pulmonary emphysema.

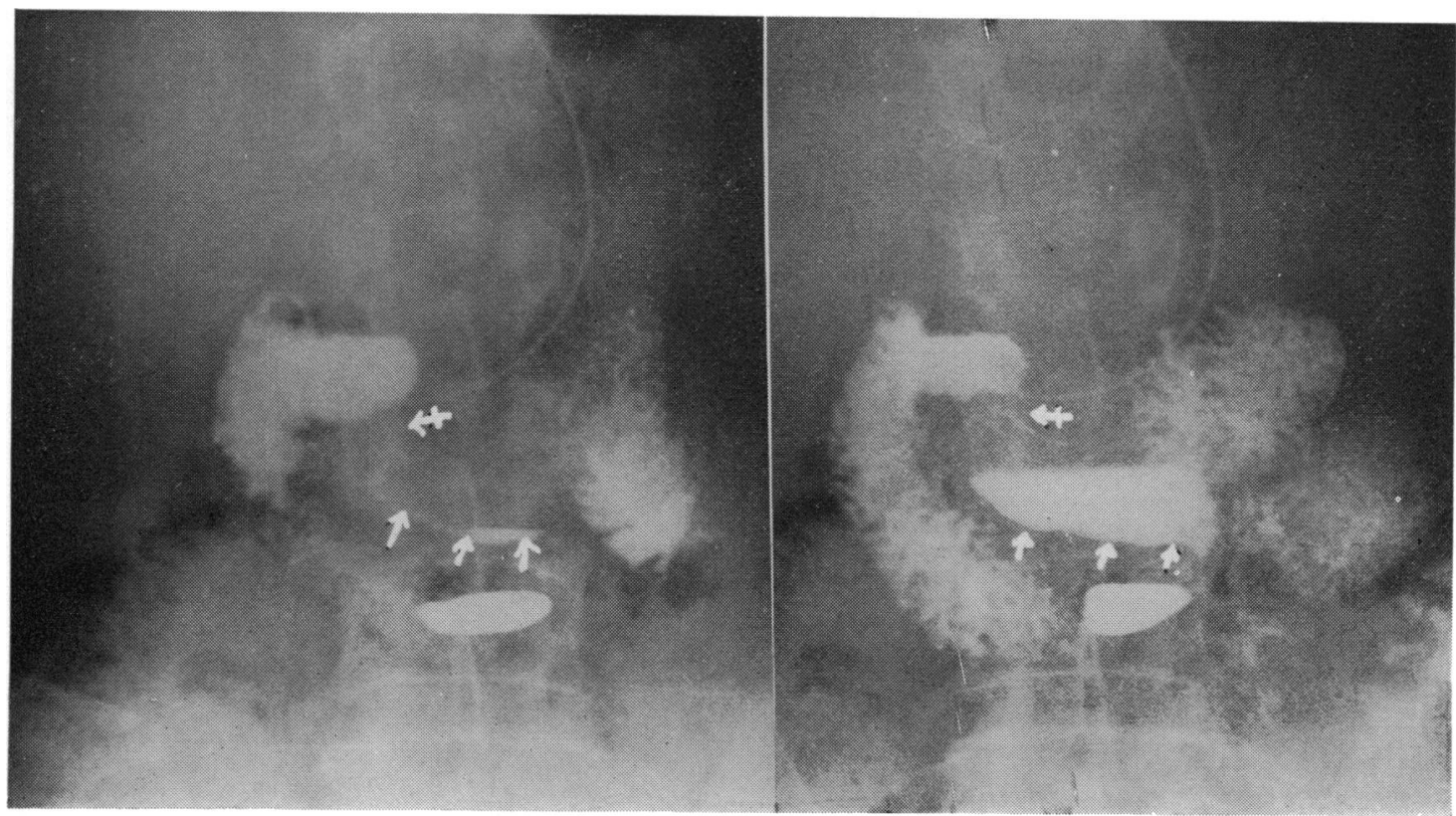

Fig. 2. Pyloric competence test (case 8). First frame shows a normal duodenal cap with early pvloric regurgitation $(\leftarrow+)$ and some gastric reflux $(\uparrow)$ in the erect position. The second frame taken a minute later shows an increase in the amount of the duodenogastric reflux. 
structural lung changes of emphysema (Reid and Millard, 1964); some patients not so labelled could have lesser degrees of emphysema without radiological changes (Laws and Heard, 1962). In all cases of emphysema the diagnosis was further supported by an impaired diffusing capacity for carbon monoxide.

\section{ASTHMA}

All patients in the series had a history of wheezing, and pulmonary function tests (FEVI/FVC) showing airway obstructions which in some cases was at least partially reversible. Only those patients whose predominant symptom was paroxysmal wheeze were classified as asthmatic.

\section{BRONCHIECTASIS}

Only those patients with bronchiectasis proved by bronchograms were considered to be suffering from that disease.

\section{PNEUMOCONIOSIS}

One patient in the series had been so labelled by the Pneumoconiosis Panel and had appropriate chest radiographs and a history of exposure.

\section{Methods}

\section{RADIOLOGICAL EXAMINATION}

All patients were examined radiologically to assess the competence of pyloric sphincteric action (Fig. 2) using a technique described in an earlier communication (Grech, 1970). Controls for the procedure were described in that paper, where 11 of the
12 controls showed a competent pylorus; it is significant that the patient with reflux suffered from bronchitis.

After testing for pyloric competence the duodenal tube was withdrawn and the patient given 6 ounces of weak barium suspension to drink. A search for gastric ulcer, hiatus hernia, and oesophageal reflux was then carried out. Results are given in Table I.

\section{MEDICAL ASSESSMENT}

\section{Upper gastrointestinal symptoms}

An inquiry for recent gastrointestinal symptoms was carried out: for simplicity, acid or water brash, heartburn or retrosternal burning were recorded as 'regurgitation', belching was separately classified, and abdominal pain of dyspeptic type was recorded as 'pain'. These symptoms are charted in Table I.

\section{Clubbing and right-sided heart failure}

The presence of clubbing was recorded in view of its possible association with disturbance of the autonomic nervous system (Holling, 1967). Patients were examined for current right-sided heart failure as patients dying of heart failure secondary to lung disease, unlike those dying of heart failure due to other causes, show a high prevalence of acute peptic ulceration (Flint and Warrack, 1958).

\section{Medication and smoking}

Current medication with steroids was noted in view of reports of its association with peptic ulceration. Whether bronchodilators were being administered and whether the patient currently smoked was also recorded.

\begin{tabular}{|c|c|c|c|c|}
\hline Case & Age & Diagnosis & $\begin{array}{l}\text { Degree of Reflux and Other } \\
\text { Gastrointestinal Findings }\end{array}$ & Gastrointestinal Symptoms \\
\hline 1 & 61 & Chronic bronchitis & Moderate & Belching \\
\hline 2 & 66 & Chronic bronchitis & Moderate & Pain, regurgitation \\
\hline 3 & 25 & Chronic bronchitis, emphysema & Moderate & Belching, regurgitation \\
\hline $4^{1}$ & 51 & Chronic bronchitis, emphysema & None & Nil \\
\hline 5 & 54 & Chronic bronchitis, emphysema & Moderate, gastric ulcer & Pain \\
\hline 6 & 55 & Chronic bronchitis, emphysema & Moderate & Belching \\
\hline 8 & 59 & Chronic bronchitis, emphysema & Moderate & Pain, belching \\
\hline 9 & 61 & Chronic bronchitis, emphysema & Marked & Nil \\
\hline 10 & 66 & Chronic bronchitis, emphysema & Moderate & Nil \\
\hline 11 & 51 & Chronic bronchitis, emphysema $( \pm)$ & Moderate & Nil \\
\hline 12 & 57 & Chronic bronchitis, emphysema $( \pm)$, pneumoconiosis & Moderate & Pain, regurgitation \\
\hline 13 & 62 & Chronic bronchitis, emphysema $( \pm)$, bronchiectasis & Marked & Nil \\
\hline 14 & 48 & Chronic bronchitis, bronchiectasis & Moderate & Nil \\
\hline $15^{1}$ & 52 & Chronic bronchitis, bronchiectasis & None & Pain, regurgitation \\
\hline 17 & 60 & Emphysema (unilateral) & Moderate & Nil \\
\hline 18 & 22 & Asthma & Moderate & Nil \\
\hline 19 & 53 & Asthma & Mild, hiatus hernia & Pain \\
\hline
\end{tabular}

Table I Gastrointestinal symptoms and radiological findings in chronic non-specific lung disease 


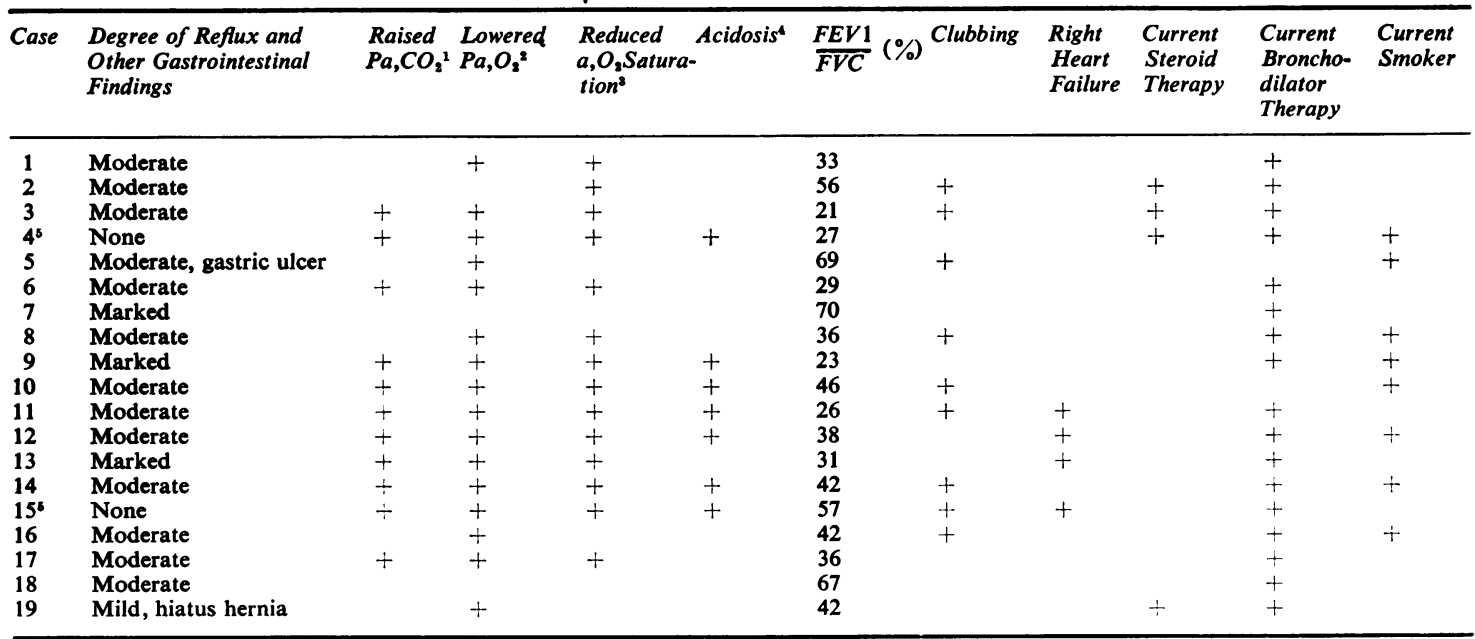

Table II Degree of duodenogastric reflux, physiological studies, and clinical features

${ }^{1}$ Raised $\mathrm{Pa}, \mathrm{CO}_{2}>47 \mathrm{~mm} \mathrm{Hg}$

'Lowered $\mathrm{Pa}, \mathrm{O}_{2}<75 \mathrm{~mm} \mathrm{Hg}$

'Lowered a, $\mathrm{O}$, saturation $<93 \%$

Acidosis $p \mathrm{H}<7.35$

${ }^{5}$ Cases without reflux

\section{Blood gas tensions}

Arterial puncture, whilst the patients breathed air at rest, was performed in each patient as close to the day of the pyloric radiological study as possible; in many cases it was performed on the same day. Arterial blood tensions of carbon dioxide and oxygen and arterial $p \mathrm{H}$ were estimated and oxygen saturation was derived from the results. In addition, $\mathrm{pCO}_{2}$ was measured by the rebreathing method as a check on carbon dioxide levels.

\section{Results}

Of the 19 patients with chronic non-specific lung disease, all of whom had chronic bronchitis, emphysema, or asthma, $17(89 \%)$ showed pyloric incompetence in the standing position which usually disappeared when lying supine; in the majority duodenogastric reflux was of moderate or marked degree.

Patient 5 was also shown to have a gastric ulcer in association with moderate reflux, and when the ulcer had healed radiologically the degree of reflux had diminished to mild. Patient 19 , the only woman in the series, showed slight pyloric incompetence and a small sliding hiatus hernia. Oesophageal reflux was excluded in all the patients.

Dyspeptic symptoms were common in the patients studied but there was little correlation between their upper gastrointestinal symptoms and the degree of reflux.

The results of the pyloric competence test and the patients' dyspeptic symptoms are shown in Table I.

We were interested to determine whether disturbance of arterial blood gas tensions or $p \mathrm{H}$ influenced the competence of the pylorus. Table II illustrates that, whilst deviation from normal values was common in most of the patients studied, two with reflux showed no deviation from normal values and, indeed, two patients with no reflux had marked lung failure and a disturbed $p \mathrm{H}$.

All patients, including those without reflux, had in common evidence of obstructive airways disease as judged by FEVI/FVC. Neither clubbing nor the presence of right-sided heart failure was necessarily present for reflux to occur.

Steroid therapy was being administered in four of the patients. Bronchodilators were currently in use in all except two of the patients, but both of these exhibited pyloric incompetence. Approximately half the patients were smokers.

The above findings are summarized in Table II.

\section{Discussion}

Whilst there is dispute about reports of an increased incidence of chronic peptic ulcer in emphysema, it seems certain that acute gastric ulcers are found more commonly in patients who die with emphysema than in those who die from other causes. In 1958 Flint and Warrack demonstrated that acute gastric ulcer was far more common at necropsy in patients dying with emphysema than in patients dying of other causes, including cardiac failure unassociated 
with chest disease. This finding was confirmed by Platts (1960) who found a similar prevalence of acute peptic ulcer at necropsy in patients with cor pulmonale, although in contrast to some other workers, she was unable to find an increased incidence of chronic ulcers.

The aetiology of acute gastric ulceration is likely to be multifactorial. Patients with chronic nonspecific lung disease may be at special risk of peptic ulceration due to augmentation of gastric acidity by steroids (Cushman, 1970), hypoxia or carbon dioxide retention (Ellison, Ellison, Carter, Daniell, and Moore, 1964), or increased histamine production (Wright, 1952). The variety of drugs administered orally, sputum swallowed, and smoking may act as gastric irritants and visceral hypoxia may reduce mucosal resistance; certainly they are all under constant stress (Shay, 1959). If an ulcer occurs, the increased splanchnic blood flow reported in hypercapnia and hypoxia (Bean and Sidky, 1958) may lead to a special risk of haemorrhage.

High acid levels are not necessary for gastric ulceration and the hypoxia of heart failure does not appear to lead to a high incidence of acute gastric ulcer. A priming factor for acute gastric ulceration in chronic non-specific lung disease may prove to be duodenogastric reflux demonstrated in $89 \%$ of the patients we studied. The increased rate of healing of gastric ulcers during bed rest may be explained by the lessening of reflux in the supine position.

We thank Drs C. S. Darke, F. J. Flint, and E. G. Rhind for their encouragement and for allowing us to study their patients.

\section{References}

Bean, J. W., and Sidky, M. M. (1958). Intestinal blood flow as influenced by vascular and motor reactions to acetyl choline and carbon dioxide. Amer. J. Physiol., 194, 512-518.

Capper, W. M., Airth, G. R., and Kilby, J. O. (1966). A test for pyloric regurgitation. Lancet, 2, 621-623.

College of General Practitioners Respiratory Diseases Study Group (1961). Chronic bronchitis in Great Britain. Brit. Med. J., 2, 973-979.

Cushman, P., Jr. (1970). Glucocorticoids and the gastrointestinal tract : current status. Gut, 11, 534-539.

Davenport, H. W. (1968). Destruction of the gastric mucosal barrier by detergents and urea. Gastroenterology, 54, 175-181.

Delaney, J. P., Cheng, J. W. B., Butler, B. A., and Ritchie, W. P., Jr. (1970). Gastric ulcer and regurgitation gastritis. Gut, 11, 715719.

Ellison, L. T., Ellison, R. G., Carter, C. H., Daniell, D., Jr., and Moore, V. A., Jr. (1964). The role of hypercapnia and hypoxia in the aetiology of peptic ulceration in patients with chronic obstructive pulmonary emphysema. Amer. Rev. resp. Dis., 89, 909-916.

Flint, F. J., and Grech, P. (1970). Pyloric regurgitation and gastric ulcer. Gut, 11, 735-737.

Flint, F. J., and Warrack, A. J. N. (1958). Acute peptic ulceration in emphysema. Lancet, 2, 178-179.

Grech, P. (1970). A technique for assessing pyloric reflux. Gut, 11, 794-795.

Green, P. T., and Dundee, J. C. (1952). The association of chronic pulmonary emphysema with chronic peptic ulceration. Canad. Med. Ass. J., 67, 438-439.

Holling, H. E. (1967). Pulmonary hypertrophic osteoarthropathy. Ann. intern. Med., 66, 232-234.

James, A. H., and Pickering, G. W. (1949). The role of gastric acidity in the pathogenesis of peptic ulcer. Clin. Sci., 8, 181-210.

Laws, J. W., and Heard, B. E. (1962). Emphysema and the chest film: a retrospective radiological and pathological study. Brit. $J$. Radiol., 35, 750-761.

Overholt, B. F., and Pollard, H. M. (1968). Acid diffusion into the human gastric mucosa. Gastroenterology, 54, 182-189.

Platts, M. M. (1960). Peptic ulceration and gastric acid secretion in patients with chronic respiratory acidosis. Gastroenterology, 38, 317-323.

Reid, L., and Millard, F. J. C. (1964). Correlation between radiological diagnosis and structural lung changes in emphysema. Clin. Radiol., 15, 307-311.

Shay, H. (1959). Emotional stress and parietal cell mass. Amer. J. dig. Dis., 4, 846-870.

Simon, G. (1964). Radiology and emphysema. Clin. Radiol., 15, 293306.

Watkinson, G. (1951). A study of the changes in $\mathrm{pH}$ of gastric contents in peptic ulcer using the $24 \mathrm{hr}$. test meal. Gastroenterology, 18, 377-390.

Wright, S. (1952). The role of histamine in the body. In Applied Physiology, 9th ed., p. 338. Oxford University Press, London. 